\title{
Belo Horizonte das primeiras décadas do século XX: entre a cidade da imaginação à cidade das múltiplas realidades
}

\author{
Julia Calvo*
}

\begin{abstract}
Resumo
Belo Horizonte se traduz como cidade singular por sua constituição, seu contexto e planejamento. Neste artigo, nos debruçamos na discussão de Belo Horizonte e suas imagens complementares: a de cidade republicana e a de cidade moderna. Essas imagens são analisadas aqui no momento da promessa, como uma cidade que foi idealizada e planejada, e também nos primeiros anos de sua ocupação já como cidade realizada e percebida pelos grupos que dela participam.
\end{abstract}

Palavras-chave: Belo Horizonte; Cidade moderna; República brasileira; capital do Estado de Minas Gerais.

Belo Horizonte foi uma cidade planejada construída em três anos e inaugurada em 1897. Da sua aprovação como nova capital do Estado mineiro à sua ocupação, desdobram-se e se entrecruzam as matizes, as inspirações e as influências que se sustentaram na cidade de promessa para a cidade da concretude. Nesse processo são revelados paradoxos que compõem o universo das cidades modernas e busca-se, no ordenamento do espaço, a constituição de uma estrutura e de um funcionamento eficiente. Contudo, a cidade ao crescer adquire problemas, que ao tornarem-se cada vez mais complexos, estabelecem dinâmicas que geram exclusão, conflitos e desordenamento. Vão se destacando as dissidências e resistências, as idealizações e desilusões, as distâncias e aproximações entre o discurso da cidade imaginada e a cidade construída e percebida pelos seus habitantes.

\footnotetext{
* Doutoranda em Ciências Sociais pela Pontifícia Universidade Católica de Minas Gerais, mestre em Educação pela Universidade Federal do Mato Grosso (UFMT). Professora da PUC Minas e pesquisadora do Instituto Histórico Israelita Mineiro (IHIM).
} 
A proposta deste artigo é refletir sobre a passagem da cidade planejada (da promessa) à cidade realizada, através dos registros da percepção dos seus grupos. Nossa análise de Belo Horizonte como objeto, se apoia em duas imagens complementares: o de cidade republicana e o de cidade moderna. A primeira imagem destaca o contexto nacional que incluiu a mudança da antiga capital, Ouro Preto, e a construção da nova cidade. A imagem de cidade moderna relaciona-se, com a influência europeia do século XIX, marcadamente pela reurbanização das grandes cidades e das inovações técnicas e transformações nas rotinas, nas relações de trabalho e no progresso material do período.

\section{Cidade Republicana}

Belo Horizonte carrega como marca de nascimento o contexto republicano. É justamente a implantação da República que promove a consolidação dos esforços para desenrolar a questão da mudança da capital.

No contexto vivenciado pelo Estado mineiro de perda dos espaços políticos significativos, após o declínio da atividade mineradora, a construção da capital apresentava um sentido de resgatar o espaço nacional do Estado e readequar valores à estrutura tradicional dos grupos políticos aqui residentes. É importante ressaltar que o Projeto de transferência da sede do poder publico mineiro para um centro urbano surgiu de três concepções disseminadas entre as elites mineiras nos anos de 1880 e 1890: a estagnação da economia mineira e seu atraso em comparação ao crescimento do centro econômico do país (representado pelo Rio de Janeiro e por São Paulo) ${ }^{1}$; a ênfase na dissociação entre o poder político e o poder econômico em Minas Gerais (contraste entre a imagem das regiões mais dinâmicas - sul e da mata - à capital político administrativa Ouro Preto; a substituição de um símbolo decadente (monarquismo-Ouro Preto), por outro moderno e no seu tempo (AGUIAR, 2006, p. 34-35).

Nesse quadro o planejamento da nova capital é definido como uma capital que se apresenta não só como uma necessidade latente para a administração estadual, mas principalmente como o lugar do novo e da república na paisagem nacional e assim, a imagem de cidade republicana se assenta como uma tentativa da materialidade da Constituição Brasileira de 1891.

\footnotetext{
${ }^{1}$ É importante ressaltar que as regiões sul e da mata, em Minas, estavam prósperas e integradas ao setor agroexportador cafeeiro, dessa forma, a ideia de estagnação é mais uma imagem em oposição a um passado de riqueza e prestigio promovido durante o ciclo do ouro e, de forma contemporânea, reflexo da comparação com outras regiões do Brasil, que haviam avançado muito economicamente (AGUIAR, 2006, p. 34).
} 
O texto da primeira Constituição da República brasileira incluiu a legitimidade dos direitos concernentes à liberdade, à segurança individual e à propriedade. Também oficializou a condição de igualdade de todos perante a lei, a legalidade da prática da livre associação, a possibilidade de representação ampla junto aos poderes públicos, o direito da livre manifestação do pensamento pela imprensa, o fim da exigência de posses/riquezas para votar e candidatar-se a cargos públicos.

Dentro dos princípios de laicização do estado foi estabelecida em termos da Lei, no artigo 72 a liberdade de culto, determinando que nenhum cidadão brasileiro por motivo de crença ou função religiosa poderia ser privado de seus direitos civis e políticos e nem eximir-se do dever cívico, garantiu também o reconhecimento exclusivo do casamento civil, o caráter secular dos cemitérios, a determinação do ensino público como leigo e a extinção de formas de subvenção de culto ou igreja que indicassem formas de aliança entre religião e Estado. Em síntese, a primeira Constituição da República foi, pelo menos em discurso, uma tentativa de concretizar os princípios republicanos por meio da garantia legal da liberdade e da igualdade entre os cidadãos, independente de nascimento, credo ou classe social e da promoção de uma separação entre Igreja e Estado que configuraria um princípio laico de sociedade e que se nortearia pelo cumprimento das leis como num pacto entre os cidadãos, definindo uma sociedade civil organizada.

Esse discurso, fundamentado sob os princípios legais, também se traduziu no sentimento de otimismo que refletia os ideais de mudança e a modernização divulgados no país. Nesse contexto, Minas Gerais introduziu uma vestimenta "nova" sobre uma antiga reivindicação que já aparecia desde o século XVIII no seu repertório: a mudança da capital mineira.

A mudança da capital advinha dos apontamentos da necessidade de uma capital que comportasse as transformações da sociedade brasileira e que se concretizou, após o golpe republicano, fortalecida com a possibilidade de materialização dos princípios republicanos na nova sede do Estado mineiro.

Nesse clima de otimismo, com a ideia de progresso associada às inovações no campo jurídico, Belo Horizonte representou os interesses de um grupo "mudantista"2

\footnotetext{
2 A utilização da expressão "mudantista", ao invés de mudancista como utilizada por outros autores, reflete a escolha da autora em manter a expressão originalmente utilizada por Abilio Barreto, na obra Memória Descriptiva de Bello Horizonte.
} 
que, desde 1821, discutia a insuficiência de Ouro Preto ${ }^{3}$ e apontava a necessidade da mudança para uma cidade que se adequasse ao crescimento em importância da capital mineira (riqueza e território).

A proposta de mudança da capital mineira já aparecia nos programas dos conjurados mineiros em 1789, assentada na proposta de implantação do regime republicano no país. Naquele momento, segundo as aspirações dos inconfidentes, a nova capital deveria ser São João Del Rey.

Barreto (1936, p. 204) aponta as causas da mudança tardia como relacionadas ao contexto monárquico, considerado centralizador "[...] de vontades, de pensar e de poder". Com a proclamação da República, novos debates nas tribunas e na imprensa colocaram como questão central e revigorada a mudança de capital, dando início ao processo que culminou com a construção de Belo Horizonte (antigo Curral Del Rey), inaugurada em 1897. Em Minas, a mudança da capital tornou-se um projeto político com a meta de reordenamento do estado para permitir o desenvolvimento econômico (AGUIAR, 1996, p. 36).

A proclamação da república no Brasil não significou grandes transformações na organização do estado. Constitui uma mudança política negociada resultado da aliança entre civis e militares. É importante no contexto de construção da nação que vai se pautar pela busca de um modelo político que proporcionasse o fortalecimento do Estado Nacional.

Em Minas, Belo Horizonte vai simbolizar a capital da república (como a noiva para a república na análise de Ciro Bandeira de Mello), constituída sob os novos ventos nacionalizantes, porém politica e estruturalmente complexas.

A autorização para a transferência da capital veio com o art. $2^{\circ}$, do Decreto n. 7 , em 20 de novembro de 1889. A permissão da mudança de capital em qualquer estado brasileiro tinha como objetivo a criação de um instrumento legal aos governadores para ação em caso de resistência ao novo regime. Em Minas Gerais não ocorreu uma resistência, porém, com a abertura legal, consagra o ideal de mudança que já se apresentava desde o século XVIII (ARRUDA, 2011, p. 53).

\footnotetext{
${ }^{3}$ Abílio Barreto (1936b), na sua obra do volume II, apresenta cinco momentos de discussão da mudança da Capital Mineira: 1879, 1821, 1883, 1851 e 1867. Todos estes momentos foram reprimidos pela própria institucionalização do governo monárquico: em 1779, o Brasil era colônia de Portugal, em 1821 vivenciava a experiência de centro administrativo, durante o império luso-brasileiro (a partir de 1808) e, posteriormente, mesmo com a condição de nação independente (após 1822) permanecia sob o jugo do monarca, mantendo os interesses do sistema político centralizado e associando a permanência da capital da província mineira em Ouro Preto, à manutenção de um sistema provincial dependente de um Estado Central, controlador das decisões políticas e definidor das prioridades e dos investimentos.
} 
Mudar a capital, entretanto, significava, na gestão pública, uma promoção de esforços e investimentos que acabariam por fortalecer a autonomia provincial. Belo Horizonte apresentou uma exaltação da ordem, nos espaços e na administração como discutiremos aqui, que lhe consagraria o novo status de suficiência/autonomia/independência defendido na escolha de um sistema federativo para a República brasileira.

As bases republicanas brasileiras se estabelecem no manifesto republicano de 1870, em que expõem no discurso brasileiro: a defesa da laicização do Estado como ideal do exercício da participação, da liberdade e da igualdade; a afirmação do pacto entre cidadãos e a constituição de uma sociedade civil organizada; a crítica ostensivamente à monarquia como símbolo da miséria e da opressão; tradução de certa confusão entre a monarquia e a pessoa do imperador, em especial à princesa Isabel (OILIAM, 1960, p. 29-30).

Já em Minas, a adesão republicana se dá tardiamente com o Manifesto dos Republicanos Mineiros (1888), que refletia o teor geral das campanhas que os partidos republicanos já desenvolviam. É significativo o diminuto entusiasmo e apoio na campanha republicana em Minas, assim como, também aqui, não houve discussão acerca da forma republicana que seria adotada quando o movimento saísse vitorioso (dividida em unitária ou federativa), a principal questão que unia os republicanos mineiros era a campanha de oposição ao abolicionismo e a consequente eliminação da monarquia no país ${ }^{4}$.

A escolha do sistema federativo, sob a influência do modelo de República dos Estados Unidos, impunha a ordenação dos conflitos provinciais que se manifestaram em momentos de crise da unidade brasileira, como durante as lutas internas após a emancipação e nas revoltas regenciais. Adotar o modelo federativo significava a valorização da autonomia dos Estados, porém, na prática, significava a conciliação, por meio dos ajustes, dos interesses das elites do país para que o fim da monarquia se concretizasse. É importante destacar que a cidade de Belo Horizonte vai estabelecer essa nova ordem federativa na distribuição espacial dos prédios e das secretarias,

\footnotetext{
${ }^{4}$ A Defesa dos Republicanos para eliminação da Coroa apresentava as seguintes razões: esgotamento da capacidade realizadora do império; incapacidade administrativa dos membros da família Real, especialmente da princesa Isabel, herdeira do trono; intolerância da mesma princesa, em matéria religiosa; necessidade inadiável de participação do povo no governo; impossibilidade da continuação da vitalicidade do Senado, do Poder Moderador e da Centralização administrativa; negação do Império em admitir a responsabilidade do chefe do Estado; urgência de separar a Igreja do Estado (OILIAM, 1960, p. 64-65).
} 
representando simbolicamente a autonomia dos poderes e a relação orgânica com a administração estadual. Na prática significou uma ameaça já que estabelecia o poder descentralizado mas que, em Minas, significou a reafirmação de um discurso de conciliação da nossa elite política.

Quando implantada a República, a elite política em Minas se une em torno da república com o estabelecimento da ideia de conciliação, assumida como busca de equilíbrio entre ordem e liberdade. Nessa representação da conciliação entre as elites tem vez a ascensão, em Minas, do discurso libertário, construído no culto aos inconfidentes (e a Tiradentes) como identidade.

Em Minas, conciliação significou uma forma de continuidade na mudança, segundo Dulci (1984, p. 22): “[...] conciliação é transigência, visando a evitar rupturas [...]" e claro, resguarda o equilíbrio, traço da identidade do mineiro, da "mineiridade".

Dessa forma, é possível afirmar que a Minas Gerais republicana buscou na tradição e na luta libertária a sua identificação do regime republicano com a nação. Não significou uma ruptura, como pode-se pensar no modelo das republicas européias como fruto da revolução e ascensão de uma nova ordem política, fazia-se necessário em Minas uma associação com o passado, principalmente com o passado dos inconfidentes e a capital significou uma justaposição entre tradição e futuro, novo e velho, moderno e antigo, justificando e glorificando a República como transformação (MELLO, 1996, p. 13).

Apresenta-se aí o primeiro paradoxo do republicanismo no Brasil: como construir uma imagem de participação, tradicional no ideário da República, sob resquícios de uma monarquia e, principalmente, sem existência de revolução prévia ou participação popular direta que desse significado às mudanças de poder, e, consequentemente de regime político (monarquia para república)?

Para Gomez (1995), o termo república com destaque nas origens da teoria política com Maquiavel, Milton, Harrington, entre outros, tem estado ausente das discussões teóricas da política moderna e contemporânea em contraposição à valorização do conceito de democracia.

Cabe aqui uma definição de republicanismo como, no âmbito mais amplo e geral, a forma de governo em que cidadãos organizados em sociedade, geralmente por meio do sufrágio universal, participam da definição do Estado e de seu(s) dirigente(s) e representante(s) (GOMEZ, 1995). 
Sua definição está relacionada com a tradição republicana clássica (Repúblicas grega e romana) e com seu retorno no Estado Moderno associado à Renascença italiana que via na república um retorno de inspiração aos princípios clássicos, tidos como modelos do "bem viver" e, ao mesmo tempo, uma resposta ao movimento de rejeição ao mundo do seu tempo, do final do Medievo.

Nossa discussão aponta para a ocorrência de uma seleção de elementos distintivos da cidade que caracterizariam essa ideia de "nova ordem" republicana, garantidora do equilíbrio que se apresentava. As motivações tradicionais de inspiração nas repúblicas italianas da Renascença, que orientaram em muitos momentos as transformações políticas na História vão aparecer seja nas colunas neoclássicas das construções da cidade como será discutido na arquitetura na imagem de cidade moderna, seja na propaganda da liberdade em destaque nos espaços mais valorizados da cidade construída.

O Renascimento italiano nasceu como um movimento de características urbanas e como um movimento de minorias. Marcava-se por um aspecto de subversão à ordem estabelecida (fruto das crises do século XIV), buscando nos clássicos modelos de bemviver e o discurso da liberdade.

As nações modernas utilizaram dos modelos italianos e os adaptaram para a realidade singular que cada país vivenciava. Dessa forma, o renascimento no século XVI se difunde na Europa do norte, reformulando os modelos para servirem aos interesses dos grupos e do poder (inclusive nas monarquias absolutas em ascensão). $\mathrm{O}$ iluminismo, enquanto processo de ideias, vai promover o resgate de alguns dos antigos valores do Renascimento, principalmente o da liberdade, na construção dos ideais da nova sociedade sob a égide liberal burguesa.

A capital do Estado refletiu o discurso republicano construído sob as bases da busca do equilíbrio e apoiada no pensamento progressista que invadiu as principais capitais do país na segunda metade do século XIX. Tal corrente no Brasil tomava como base ideológica o positivismo, defendendo o progresso em uma situação de harmonia, ausência de conflitos na manutenção de um status quo garantidor da ordem e, consequentemente, do desenvolvimento. A transformação da nova capital associava à República mineira e brasileira uma relação com a história simbólica das lutas e da tradição, simbolizada e reinterpretada nas avenidas e ruas (que traziam os nomes dos estados e das bacias fluviais). 
Os ideais renascentistas vão aparecer sob essa nova roupagem, adaptados para a realidade da nova cidade e de sua elite política, no final do século XIX. Por meio da arquitetura eclética (muito influenciada pelo neoclassicismo, indicativa da exaltação dos clássicos) e de uma simbologia instituída nos espaços da cidade, Belo Horizonte destacou a liberdade como ideal e definiu uma organização de poderes que encenavam uma participação.

Para construir tudo isso foi preciso um exército de braços trabalhadores e, dessa forma foi intensificado o apelo à imigração (BARRETO, 1936a). Deu-se início a construção de uma infraestrutura específica e da aprovação de um detalhamento normativo para garantir que as obras da nova cidade caminhassem como desejável pela Comissão Construtora da Capital. Foram construídas linhas férreas para transporte de pessoas e de material, foi criada uma Hospedaria de Imigrantes que a Inspetoria de Terras e Colonização usava para abrigar os trabalhadores estrangeiros ${ }^{5}$ e, para evitar que os responsáveis pela condução das obras, os tarefeiros, aliciassem trabalhadores uns dos outros, o ofício n. 469, da Comissão construtora da capital, estabelecia que para o recebimento de tarefas fazia-se imprescindível ao empregador trazer de fora o pessoal correspondente ao trabalho contratado.

A cidade com linhas modernas acomodou funcionários, militares, clero, trabalhadores por meio da construção de ruas largas, edifícios firmes e esculpidos em concreto e de uma divisão simbólica da cidade que separava os grupos em categorias e ordenava a cidade do ponto de vista físico e social.

Belo Horizonte foi setorializada e organizada em zonas: urbana, suburbana e rural, definindo assim a ocupação dos grupos e seus espaços. A corporificação da ordem se fazia na constituição dos espaços definidos a partir da noção de estar fora ou dentro dos limites da Avenida do Contorno.

Essa organização republicana carregava a influência do positivismo em que a abstração e o rigor geométrico "[...] professavam a utopia de se traçar com régua e o compasso uma ordem social harmônica, unitária, onde não haveria lugar para a chamada desordem urbana”. (JULIÃO, 1992, p. 56).

\footnotetext{
5 A hospedaria localizou-se à margem da linha férrea do Ramal, próximo a uma das suas estações e distante do centro dos trabalhos. Era um edifício de madeira sobre pilares de tijolos e cobertura de zinco com capacidade para 200 pessoas, preferencialmente solteiros. Contava com acomodações para solteiros e para famílias, salão administrativo, rouparia, pequena enfermaria, salão de jantar, salão para copa e cozinha, closets e banheiros para ambos os sexos num anexo separado (BARRETO, 1936b).
} 
Fazia-se assim necessário, para os defensores do regime republicano, gradualmente construir uma imagem de República no país, que incluía além do ideal de liberdade as noções da defesa da cidadania e dos princípios de participação na valorização do bem coletivo. Belo Horizonte refletiu essa tentativa de traduzir os princípios do republicanismo na constituição de espaços da cidade: os planificadores da cidade, no caso a Comissão Construtora, revelam-se como os manipuladores por excelência do meio ambiente físico e se mostram interessados ao planejar os espaços, na interação que produz a imagem deste meio ambiente (LYNCH, 1996).

Oportunizaram a construção de um mundo citadino como sendo uma paisagem ideal que impõem aos habitantes da cidade uma nova atitude. As características dos objetos, equipamentos e estruturas tendem a reforçar uma imagem e a cristalização da identidade com a cidade.

\footnotetext{
Pode-se dizer que a Comissão Construtora teve uma atuação fiel aos "mandamentos" urbanísticos consagrados na Europa. Mandamentos que, segundo Benevolo, pretendiam imprimir um duplo caráter, científico e moralista, à gestão das cidades. (JULIÃO, 1992, p. 55).
}

Em Belo Horizonte, a rua tornara-se o princípio organizativo da paisagem. A arquitetura foi em grande parte importada do estilo neoclássico francês. O Traçado ortogonal, como a cidade não era plana, exigiram que os construtores fizessem novos recortes e traçados.

O ponto mais alto da cidade, totalmente planificada, recortada para se enquadrar na planta de cidade moderna foi a Praça da Liberdade. O caminho para se chegar à praça, onde foi estabelecido o centro da Administração Pública Estadual era uma avenida larga e arborizada conhecida na época da fundação como Avenida da Liberdade (hoje, Avenida João Pinheiro).

O local onde se estabeleceu a Praça da Liberdade e se instituiu o Centro Administrativo do governo constituía o lugar mais elevado da cidade e, na visão de Grossi (1997, p. 20), “[...] a acrópole, ícone visível e ostentório do poder”. Está no topo de uma colina e, para construção, foi necessário um trabalho de terraplanagem para a criação artificial da esplanada de localização dos edifícios públicos e da praça.

Para materialização da noção de liberdade e República, o conjunto arquitetônico da Praça da Liberdade ainda estava ligado, como um cordão umbilical, à Praça da República (hoje, Praça Afonso Arinos): 
A natureza unitária e geométrica desse espaço, tramado pela moderna racionalidade positivista da época, explicita o regime, legitimando o Estado de Minas que, por sua vez, se corporifica na Liberdade. A ordem simbólica efetivará a síntese das instâncias política e econômica, através daquela topografia imaginária, cuja proposta parece extrapolar o visível e imediato da proposta urbanística. (GROSSI, 1997, p. 20).

O nome de Avenida da Liberdade é a concretude do próprio espírito do republicanismo do século XIX, com suas musas e ideais que dão a representatividade do Estado de Minas Gerais daquele tempo. A direção dos prédios públicos do entorno da Praça, por sua vez, são organizados estrategicamente no espaço para construir determinadas simbologias e definições de poder (no nascente, a Secretaria de Finanças e do Interior e no Poente a da Agricultura).

\begin{abstract}
A Praça da Liberdade, considerada o espaço mais importante de uso público, era cunhada de Jardim do Palácio, por situar-se à frente do Palácio da Liberdade, projetado para residência do Presidente do Estado. As pedras fundamentais desse palácio e de três secretarias são lançadas em 07/09/1896. $\mathrm{Na}$ Praça da Liberdade, voltadas para o nascente, estão as secretarias de Finanças (hoje, Fazenda) e do Interior (hoje, Educação). Em frente à de Finanças, acompanhando o poente, situa-se a de Agricultura (atual Viação e Obras Públicas). (GROSSI, 1997, p. 20).
\end{abstract}

A Praça da Liberdade foi projetada como uma esplanada para o Palácio do Governo. No projeto original da Comissão Construtora da cidade, só o Palácio Presidencial ficaria na Praça da Liberdade, as secretarias seriam localizadas em uma praça triangular da VI seção, juntamente com os palácios do Congresso e da Justiça, na Avenida Afonso Pena ${ }^{6}$ (BARRETO, 1936a).

Seu formato como o de um tabuleiro e suas construções elegantes, que misturaram vários estilos do final do século XIX (Art-decó, da década de 1940; Moderno, dos anos 1950 e 1960; e pós-moderno, de 1980), afirmaram-se sobre um belissimo complexo paisagístico. Na construção dos edifício, apesar da variedade de estilos, merece destaque o desenho da Praça da Liberdade com um estilo fin de siécle, eclético mas com tendências marcantes do estilo neoclássico em que o traçado e os jardins inspirados no Palácio de Versalhes ${ }^{7}$ (PEREIRA; XAVIER, 1997).

\footnotetext{
${ }^{6} \mathrm{Na}$ época da edificação destes edifícios, entretanto, segundo Abílio Barreto, julgou-se mais acertado colocá-los junto ao Palácio.

${ }^{7} \mathrm{O}$ conjunto arquitetônico e paisagístico (edifícios, Palácio e antigas secretarias, os jardins, lagos, alamedas, fontes, monumentos e fachadas de edificações no seu entorno) foi tombado pelo IEPHA, em 02 de junho de 1977, institucionalizando seu valor histórico, estético e arquitetônico.
} 
Pode-se compreender Belo Horizonte como uma cidade representativa da República brasileira que carregou, no seu planejamento, os desejos de uma elite ansiosa por uma ordem que rompesse com o passado monárquico visto com opressão em favor da valorização da liberdade dos inconfidentes. Vai concretizar simbolicamente esses desejos por meio das linhas e traçados da cidade, nas avenidas, largas, nas construções ousadas, nas estruturas jurídico-administrativas, na preocupação sanitária e nos modelos de gestão administrativa.

\section{Cidade Moderna}

Belo Horizonte foi erguida para, mais que simbolizar, marcar o projeto de modernidade republicana. (PAIVA, 1997, p. 30).

Belo Horizonte, como uma cidade projetada pelas elites políticas e cujo planejamento se fez nas planilhas dos engenheiros, tinha uma perspectiva futurista e obedece à lógica do ideal de perfeição modernizante, de que qualquer problema poderia ser redimido pela técnica, pela organização dos espaços, influência do positivismo, desenhou a cidade como cidade ideal no imaginário dos planejadores ${ }^{8}$.

A outra imagem de Belo Horizonte, a de Cidade Moderna, se traduz em tudo aquilo que a cidade vai proporcionar de ordem e perfeição aos seus habitantes: desde os confortos advindos dos progressos técnicos, que tornariam o viver na cidade mais fácil do que o viver no campo, até a tentativa de imitação dos modelos e estilos do mundo europeu.

As diferenças das cidades européias para Belo Horizonte eram explícitas: enquanto na reurbanização européia o foco da construção era o combate à multidão (identificada como causa da crise na cidade, numa associação com o caos e o desordenamento), que ameaçariam o próprio funcionamento da cidade ideal, a cidade de Belo Horizonte mostrava-se uma paisagem quase intocada pelo homem. Em comum, entretanto, a ideologia de que se fazia “[...] necessário conhecer para ordenar, antecipando, na organização de mundo físico, o desenho de uma ordem social”. (JULIÃO, 1992, p. 55).

\footnotetext{
${ }^{8}$ Belo Horizonte foi pensada, inicialmente para 200.000 habitantes. Em 1920 contava com 55.563 habitante e este número dobra de tamanho em 1930, com 116.981 habitantes (ANDRADE, 2004).
} 
A noção modernizadora ${ }^{9}$ em Belo Horizonte mostrou a associação com os modelos das cidades européias tidas como modernas sob o ponto de vista da noção de metrópole e do ideal do cosmopolitismo, consagradas pela ascensão da sociedade liberal burguesa. A cidade metrópole reuniria grupos diferentes, traduzidos na impessoalidade das relações entre as pessoas permitindo as trocas monetárias e a possibilidade de que, ao compartilharem modelos comuns, as pessoas se sentissem bem em qualquer cidade metrópole do mundo.

Simmel (1987) vê a metrópole como a sede da economia monetária. É a economia do dinheiro que domina a metrópole e que vai acabar por desalojar os resquícios da sobrevivência da produção doméstica e da troca direta de mercadorias. Dessa forma, à cidade compete a mais alta divisão econômica do trabalho, onde o dinheiro torna-se o denominador comum de todos os valores, arrancando a essência das coisas e consagrando o ideal do século XVIII de libertação das dependências históricas ao Estado, Religião, Moral e Economia. O homem da metrópole reivindica a preservação de sua autonomia e individualidade frente às forças sociais o que, na sociedade liberal burguesa, vai exigir uma especialização funcional.

Nessa ótica pode-se dizer que a cidade de Belo Horizonte apresentou grandes desafios sob o ponto de vista da modernização econômica: surgiam possibilidades para o desenvolvimento material, advindas do significado de ser a sede administrativa do Estado e do crescimento de investimentos na cidade, porém, essas possibilidades esbarravam na situação de economia dependente, que se manteve por muito tempo, à sombra da herança rural da região.

Julião (1992) considera que a capital vai desenvolver uma forma de vida indefinida e híbrida que hesita entre o passado e o futuro. As ruas, avenidas e praças representavam uma ruptura radical com a tradição do urbanismo colonial mineiro, porém, plantada em meio a um "sertão", marcado pela estrutura agrária e atrasada.

A organização do espaço urbano se traduz em discurso de cidade moderna quando associada à serviços, conforto, facilidades, instituições e administração, porém, no caso de Belo Horizonte, marcava-se por um espaço-tempo ambíguo em que o homem vive a experiência de dois mundos - aquele transformado pela modernidade e outro mantido pelas tradições a que ele se liga material e espiritualmente.

\footnotetext{
${ }^{9}$ É preciso indicar que a noção de moderno como inovação se ausentou da realidade da cidade até 1940 , porém a tentativa de "copiar" modelos de fora vai criar formas, até então, novas na maneira de administrar a cidade.
} 
Andrade (2004) também valoriza a ambiguidade do homem no mundo moderno como iremos tratar ainda nesse artigo. A autora destaca que nas cidades do período moderno européias tradicionalmente se estabelece um caráter de ruptura na perda dos "muros" e do caráter fechado das cidades. O modelo de cidade moderna européia se consagra na intensidade da relação da cidade-metrópole com o mundo exterior ${ }^{10}$, materializando essa perda dos "muros" e do caráter autônomo das antigas cidades e incluindo aí a perda da idéia de comunidade e dos valores provincianos. (ANDRADE, 2004, p. 29-32).

A substituição da capital de Ouro Preto para Belo Horizonte, entretanto não vai refletir a abertura de forma sistemática e a promoção, de imediato pelo menos, da perda dos "muros". A transformação do espaço da cidade, na criação da nova capital vai ao encontro das novas necessidades da cidade moderna que exige nova configuração onde as contradições e o caos da urbanização se realizem, mas no caso de Belo Horizonte, a cidade moderna desejável não compartilha a promoção de uma ruptura tão significativa que lhe daria um caráter de cidade metrópole.

A cidade moderna tradicional tem como características o estabelecimento da moradia de massa, da multidão manifestada na diferenciação das casas pela numeração, no desaparecimento dos nomes próprios etc., porque é somente em meio à indiferença da metrópole é que a individualidade pode desenvolver-se. A cidade é formada pelas interações sociais, pelas ações recíprocas entre os homens pelas relações distintas que se estabelecem entre os pequenos e os grandes grupos (ANDRADE, 2004, p. 34-35).

Entretanto, Belo Horizonte vai ter um sentido de expansão urbana, principalmente quando consideramos a destruição do antigo Curral D'el Rey para que fosse erguida a nova capital em seu lugar. Porém, a cidade híbrida como considerou Julião, vai manter-se com características ainda de cidade pequena, marcada pelo conhecimento pessoal dos indivíduos que ali vivem e por uma participação mais direta na vida da comunidade.

$\mathrm{Na}$ perspectiva simmeliana, o individualismo moderno decorre tanto das mudanças nas condições externas vivenciadas na divisão do trabalho, no pertencimento a diferentes círculos sociais e instituição de uma ordem social mais abstrata e mais

${ }^{10}$ A presença dos estrangeiros poderia ser um reflexo da intensa relação da cidade com o mundo exterior. Os estrangeiros de forma mais ou menos sistemática trouxeram modelos de seus lugares de origem, ensinando formas de vida consideradas "modernas" e aumentando as redes de integração da cidade, principalmente pela via comercial. Entretanto, o caráter singular de cidade, nos leva à discussão se realmente é perceptível em Belo Horizonte, essa ruptura com o caráter fechado das antigas cidades. 
preocupada com o geral do que com o particular, quanto às condições subjetivas e culturais originadas na própria valorização da individualidade (ANDRADE, 2004, p. $37)$.

Nessa concepção é importante a abstração do espaço sem ignorar o incentivo à individualização que indicaria o status social dos indivíduos, percebida na moda, no número de janelas da residência, no lugar de moradia e do trabalho, na posse de bens e na escolha dos serviços (em que loja faz compra, qual restaurante frequenta, se utiliza um determinado eletrodoméstico, etc.).

A tentativa de tornar Belo Horizonte uma cidade grande passaria, principalmente, pela oferta de "facilitadores" da metrópole como serviços, comércio, transporte, infraestrutura e especialização nos serviços e do funcionalismo, o que indica a dependência com a sociedade exterior, em que indivíduos mais especializados, vinculam-se a uma maior divisão do trabalho e na relação necessária com os outros.

Do ponto de vista sócio-cultural traduziu um aspecto inovador (e até artificial da cidade), induziu os cidadãos a novos hábitos, trouxe uma nova era marcada pelo advento da modernização: água encanada, iluminação elétrica, apitos de trem. A gestão da cidade tornou-se complexa exigindo intervenções interdisciplinares (jurídica, médico-sanitarista, estatística etc.). É importante destacar que construir uma cidade moderna significava, praticamente, “copiar” um repertório urbanístico já experimentado na Europa e, para isso, era preciso importar tecnologia e materiais e, sobretudo, um estilo de vida de cidade moderna.

Em princípio, Belo Horizonte ofereceu à classe média interiorana o estilo de vida da cidade moderna: faculdades, empregos públicos e, principalmente uma vida social e cultural prometida, como mais livre e muito mais intensa do que nas cidades pequenas, indo ao encontro da representação urbana, que integrava o imaginário de uma parte das elites brasileiras no final do século XIX.

Assim como Simmel, Frisby (ANDRADE, 2004, p. 35-36) confere ao simbolismo do dinheiro no dinamismo da vida moderna a função de mediador das trocas assim como fator de indiferenciação e calculabilidade. $\mathrm{O}$ dinheiro proporciona a liberdade, já que o poder de compra significa a possibilidade de escolher entre um produto e outro, um lugar e outro e assim sucessivamente e, consequentemente, o dinheiro possibilita também a diferenciação como se percebe na moda e na sua caracterização do próprio dinamismo da vida moderna. 
A vida moderna é essencialmente marcada pela transitoriedade: de um lado, homogeneíza (com produtos e serviços mais despersonalizados), enquanto, de outro, diferencia os indivíduos (com a moda e a utilização de serviços, por exemplo).

Analisada sob essa ótica, Belo Horizonte também pode ser considerada como conservadora ao perpetuar as barreiras entre elite e setores populares e não era exatamente "moderna" no sentido de inovação do termo já que copiou o modo de vida cosmopolita e as instituições políticas burguesas.

Belo Horizonte, seu planejamento e construção obedeceram a um plano global e totalizante que simbolizava para uma parte das elites, a república na utopia de uma nova ordem que já nascia sob o signo da negação da liberdade e da igualdade, impondo um enquadramento da população, a partir de uma destinação de espaços previamente definidos sob a ótica da organização social. A arquitetura trouxe um espírito inovador sintonizado com a modernidade que rondava a Europa no século XIX, mas um modelo de amplo controle social (BUÉRE, 1997, p. 81).

A cidade trazia consigo o elemento fundamental do modernismo urbano: rua longa, larga e uniforme, diferente de Ouro Preto, a antiga capital, em que a rua era tortuosa e estreita, definida pela disposição das edificações, e todas as inovações técnicas como iluminação pública, saneamento básico e administração pública (os prédios tinham estruturas pré-moldadas importadas assim como a iluminação pública e toda infra-estrutura).

Essa imagem da rua longa, larga e uniforme é a imagem que se perpetua no imaginário da cidade realizada, ou seja, como a cidade foi vista. Essa perspectiva tornase explícita no trecho do autor Cyro dos Anjos sobre a cidade:

Largas e vazias eram as ruas da Belo Horizonte de 1923, mas tudo me parecia trepidação, formigamento, em contraste com o paradeiro que Santana me deixara na retina (ANJOS, 1994, p. 228).

Com Cyro dos Anjos evidencia-se também o grande canteiro de obras da cidade em transformação indicando crescimento, alargamento, produção. É assim, na disposição organizacional e arquitetura das ruas que se materializa a imagem de cidade moderna, mesmo que essa imagem, muitas vezes, deixe fragilidade a ideia de ocupação urbana e de vida cultural desejável pela cidade que se inspira no modo de vida europeu.

A cidade em termos de organização e espaço tentou traduzir o republicanismo como espírito de condução de política e de ordem moderna, porém, a introdução de 
novos valores e hábitos não garantiu a institucionalização do republicanismo na vida da cidade.

Paradoxalmente, a noção de cidade moderna, Belo Horizonte permanecia vinculada aos muros, ao afetivo e provincial, marcadamente, nos grupos e na relação entre os grupos da cidade, conservando valores herdados do período imperial e colonial brasileiro.

O povo continuou sem participar e o grupo constituído pela aristocracia instituiu um modelo de poder que reforçou, no caso de Belo Horizonte, inclusive no ordenamento do espaço, os ideais políticos que queriam consagrar como seus.

Como já enunciamos, Andrade (2004) trata a cidade sob dois conceitos opostos: a racionalidade, que pressupõe objetividade, ausência de afetividade e de tradição; e ambivalência ou ambigüidade, que pressupõe a coexistência de valores e/ou sentimentos contraditórios que podem ser identificados com irracionalidade. A partir dos dois conceitos analisa o discurso de autores modernistas em Belo Horizonte.

A cidade moderna é representada assim como um lugar de contrastes: pobrezariqueza, degradação-opulência, ordem-caos, liberdade-controle e assim sucessivamente, que se traduzem na grande diversidade que marca a cidade formada pela heterogeneidade de grupos, de profissões, de nacionalidades.

Os modernistas analisados por Andrade (2004) na sua obra, Pedro Nava, Carlos Drummond de Andrade e Cyro dos Anjos, vão representar Belo Horizonte como uma cidade provinciana por seu tamanho, pela característica de sua vida social e, principalmente pelo seu conservadorismo ${ }^{11}$. É o provincianismo que vai aparecer para os modernistas como a causa da exclusão da cidade de Belo Horizonte e razão da sua ambivalência. Os mineiros não eram nem cosmopolitas (aqueles que se sentem à vontade em qualquer cidade porque conhecem seus aspectos comuns) e nem provincianos por conta da característica homogeneizadora da vida moderna. Carlos Drummond de Andrade ilustra muito bem esse sentimento em relação à cidade de Belo Horizonte:

\footnotetext{
- Meu amigo, acho natural a sua curiosidade. O sr. é filho doutras terras: não conhece os nossos costumes, a nossa vida coletiva, não conhece nada... Pois saiba que está numa cidade única no planeta e mesmo em todo o cosmos. Somos muito pessoais, muito nós-mesmos. Isto aqui não cheira a Pequim, Cairo ou Bruxelas. E tem um nome original. É a Cidade do Tédio... - Hein?!
}

\footnotetext{
${ }^{11}$ Drummond ainda aponta a condição periférica de Belo Horizonte.
} 
- Não se espante. Ouça mais. O nome se justifica. Nós não temos nada que fazer, nem para onde ir, nem onde ficar. Abandonamos as ruas, que são muitas, e ajuntamo-nos aqui. Para que, para o exercício comum do bocejo. [...]

- De sorte que somos os urbanos do enfado. E esta é a Cidade do Tédio. Chamaram-na de Belo Horizonte, devido a uns poentes cor de tudo que incendeiam nosso céu, mas qual! não pegou. Nem podia pegar. Que quer dizer Belo Horizonte? Nada. Agora, meu amigo, com licença. Vou embora. Adeus. (ANDRADE, 2004, p. 159) ${ }^{12}$.

Drummond chama Belo Horizonte de "Cidade do Tédio", mostrando a insatisfação com a cidade, percebida como um grande vazio, sem intensidade que caracterizaria a expectativa do autor em relação ao ideal de cidade moderna.

A resistência à capital demonstrada pelo apelido Cidade do Tédio, de Drummond, coincide também na adoção de outros apelidos de caráter negativo adotados ainda na construção da cidade. São eles: papudopolis, poeiropolis, formigopolis, expressões que procuravam ferir os créditos do arraial às vésperas de se tornar a primeira cidade do Estado (BARRETO, 1936b, p. 413).

Os modernistas como críticos da modernidade apontam, de forma negativa, a característica da artificialidade da cidade, manifestada na separação entre o homem e a natureza, e, consequentemente uma representação negativa do homem como ser mecanizado autônomo que teria perdido parte de sua humanidade com o advento das máquinas. Definem a transitoriedade como marca da cidade moderna, destacando sua existência no acelerado fluxo de mudanças que acabariam por destruir as referências físicas, sociais e afetivas.

E os modernistas de Belo Horizonte, segundo Marques (2011), vão realizar uma aliança entre tradição e modernidade: vanguardismo literário e tradicionalismo político, numa cooptação pelas oligarquias mineiras em seu projeto de modernização conservadora: "Aliança entre tradição e modernidade é o elo (ou contradição) produzido pelo choque (ou acomodação) de dois tempos históricos é o que define o grupo de Belo Horizonte." (MARQUES, 2011, p. 21).

Marques defende que apesar do estímulo vindo de São Paulo, o modernismo mineiro teria conhecido uma dinâmica própria estabelecida na busca de equilíbrio entre a ousadia das inovações e a fidelidade ao passado.

$\mathrm{Na}$ "vida de janela", que reflete a vida provinciana de João Alphonsus, analisada por ele na obra Cenas de um modernismo de província, o ambiente provinciano é

\footnotetext{
${ }^{12}$ Trecho adaptado de "A cidade do tédio", de 1921.
} 
apresentado como "[...] universo lento, sem progressão, empedernido na 'gratuidade burocrática de domingo' [...]" (2011, p. 179), destacando a marca da ambivalência daquele que vem do interior e procura se integrar à cidade que se moderniza.

Belo Horizonte é traduzida como uma novidade, cheia de euforia de um lado, mas erguida sobre uma base de especulação e miséria. Uma cidade artificial, uma modernidade postiça.

Como tentativa de formar uma metrópole, Belo Horizonte colocou-se como um espaço excludente: ordenou as classes sociais e os grupos conforme sua importância valorativa na cidade e criou modelos de vida pautados em intervenções que iam além das soluções estritamente arquitetônicas de definição do espaço como a gestão mais complexa e interdisciplinar, mobilizando saberes externos de caráter jurídico, médicosanitário, estatísticos que respondiam às problemáticas urbanas causadas pelo adensamento populacional e já experimentadas pelas cidades industriais (miséria, carência de saneamento, doenças e revoltas sociais).

No significado geral, a cidade moderna possui um duplo e complexo significado: transforma-se em espaço onde as contradições se realizam e, por isso mesmo exigem e necessitam de ordenação política e científica. É assim que a cidade de Belo Horizonte transformou-se em discurso da modernidade:

\footnotetext{
Assim, Belo Horizonte simbolizava, para uma parte das elites mineiras, a república na utopia de uma nova ordem, que já nascia sob o signo da negação da liberdade e da igualdade com instituintes da cidadania. Símbolo do progresso e de ruptura com o passado colonial, no tocante ao seu projeto urbanístico, por outro lado, conformadora de uma ordem excludente e segregacionista do ponto de vista social. (GROSSI, 1993, p. 13-14).
}

Assim, o discurso republicano brasileiro, amparado na Constituição de 1891, e a configuração moderna pautada no planejamento urbano e ordenamento social vai marcar a cidade como símbolo do novo e da República, entretanto, a aplicação dos ideais republicanos na instituição da nova capital vai acabar por gerar a formação de nódulos de participação mesclados à própria paisagem da cidade: núcleos religiosos, associações operárias, comunidades étnicas, associação de bairros etc. Principalmente nos locais habitacionais, quanto mais a setorialização gerava formas de segregação, mais se criava noções de pertencimento e possibilitava-se a coesão de grupos. 


\section{Considerações Finais}

Quando consideramos a Belo Horizonte, a partir da ótica dos grupos, faz-se necessário descobrir se o discurso de cidade republicana e de cidade moderna é coincidente com a narrativa dos grupos sobre a cidade e de como a cidade se transforma de fato, ao se moldar ao discurso que apresenta a visão destes grupos sobre ela.

Discutir a cidade a partir das suas contradições entre, a idealização da cidade planejada e a cidade instituída e percebida por seus grupos significa perceber que os grupos interagem com a cidade transformando-a com seus novos planejamentos e suas adaptações. Transformou-se a cidade, mas também transformaram-se os discursos e o dizer sobre a cidade.

A cidade foi ocupada por gente de toda parte. Braços trabalhadores que ainda tornavam-se necessários para o grande canteiro de obras e a manutenção dos serviços que a cidade apresentava; funcionários e burocratas para gerir o novo e ordenar a grande cidade; profissionais liberais da saúde, da construção, do comércio e de todo lugar para caracterizar o moderno e dar funcionalidade; gente para encher as ruas longas e largas, para ocupar os bancos da universidade, as mesas do bar, as cadeiras do bonde, do cinema, do teatro.

Vir para a capital mineira significava, nas primeiras décadas do século $\mathrm{XX}$, a possibilidade de começar a vida numa cidade nova, portanto cheia de oportunidades e também de evidentes carências da cidade imberbe que se estabelece.

Significava adotar o estilo de vida metropolitano, com seus confortos, mas com padrões de consumo e organização que impunham modos de ser e viver próprios de Belo Horizonte.

Acima de tudo, vir para uma cidade planejada pelos idealizadores a serviço de uma elite política tradicional significa servir a cidade, servir aos seus princípios, conjugar o verbo inovar associado à conservação de um modelo descrito e escrito nas motivações do discurso mudantista.

O discurso mudantista expunha a necessidade de uma cidade que atendesse às necessidades do mundo que se transformara, mas principalmente, a oportunidade de reinscrever Minas no contexto político brasileiro da ótica do poder.

Minas representava, no século XVIII, a mais populosa e rica província do Brasil e isso refletiu, no início do século XIX, a participação política da elite mineira. Criar a capital da República trazia Minas à cena novamente e destacava a elite tradicional. 
Começar a vida é a ideia da novidade da cidade para quem vem, mas é preciso lembrar sempre que é um começo de vida em uma cidade que já nasce bem definida sob padrões rígidos da orientação de um poder que se estabeleceu num mundo distante do moderno, formado num momento anterior de Brasil, onde prevalecia a ordem da tradição. 
Belo Horizonte in the first decades of the twentieth century: from the city of imagination to the city of multiple realities

\begin{abstract}
The city of Belo Horizonte is unique because of its planning and construction context. In this article, we analyze Belo Horizonte and its complementary images of a Republican city and a modern city. These images arose with the announcement of its construction - as an idealized and planned city -, as well as in its early years of occupation, as a city already built and perceived by the groups who belong to it.
\end{abstract}

Keywords: Belo Horizonte; Modern city; Brazilian Republic; Capital of the state of Minas Gerais.

\title{
REFERÊNCIAS
}

AGUIAR, Tito Flávio Rodrigues. Vastos subúrbios da nova capital: formação do espaço urano na primeira periferia de Belo Horizonte. Tese de doutoramento apresentada ao Programa de Pós-Graduação em História da Universidade Federal de Minas Gerais.Orientadora: Dra. Regina Helena Alves da Silva, 2006 (não-publicada).

ANDRADE, Carlos Drummond de. A bolsa e a vida. 8 ed. Rio de Janeiro: Record, 2008.

ANDRADE, Luciana Teixeira de. A Belo Horizonte dos modernistas: representações ambivalentes da cidade moderna. Belo Horizonte: PUC Minas, 2004. (coleção Política \& Sociedade).

ANJOS, Cyro dos. A menina do sobrado. Rio de janeiro: Garnier, 1994.

ARAUJO, Lais Correa de (Org.). Sedução do Horizonte. Belo Horizonte: Fundação João Pinheiro, 1996.

ARENDT, Hannah. Sobre a Revolução. Lisboa: Moraes, 1971.

ARRUDA, Rogério Pereira. Cidades-capitais imaginadas pela Fotografia: La Plata (Argentina) e Belo Horizonte (Brasil), 1880-1897. Tese de doutoramento apresentada ao Programa de Pós-Graduação em História da Universidade Federal de Minas Gerais. Orientadora: Dra. Maria Eliza Linhares Borges, 2011. (não-publicada) 
BALEEIRO, Aliomar. Constituições brasileiras: 1891. Brasilia: Senado Federal/Ministério da Ciência e Tecnologia/Centro de Estudos Estratégicos, 2001. (Coleção Constituiçãoes Brasileiras. v.2).

BARRETO, Abilio. Bello Horizonte: Memoria Historica Descritiva. Belo Horizonte: Livraria Rex, 1936a. (v.1)

BARRETO, Abilio. Bello Horizonte: Memoria Historica Descritiva. Belo Horizonte: Livraria Rex, 1936b. (v.2)

BARROS, José D’Assunção. Cidade e História. Petrópolis: Vozes, 2007.

BUÉRE, Julio Cesar. Apropriação Social do Espaço Urbano. In: PAIVA, Eduardo. (Org.). Belo Horizonte: Historias de uma Cidade Centenária. Belo Horizonte: Faculdades Integradas Newton Paiva, 1997, p. 65-85.

CUPERSCHMID, Ethel Mizrahy. Judeus entre dois mundos: A formação da Comunidade Judaica de Belo Horizonte (1922-1961). Dissertação apresentada no curso de mestrado em História da Faculdade de Filosofia e Ciências Humanas da Universidade Federal de Minas Gerais. Orientadora: $\operatorname{Dr}^{a}$ Maria Efigênia Lage de Resende. (não publicada), 1997

DULCI, Otavio Soares. Elites mineiras e a conciliação: a mineiridade como ideologia. In. ANPOCS - Associação Nacional de Pós-Graduação e Pesquisa em Ciências Sociais. Ciências Sociais Hoje, 1984. p. 7-29. (Anuário de Antropologia, Política e Sociologia).

DUTRA, Eliana de Freitas (Org.). BH: horizontes históricos. Belo Horizonte: C/Arte, 1996.

GÓMEZ, Antonio Velasco. Republicanismo. In. RABOTNIKOF, Nora, VELASCO, Ambrosio, YTURBE, Corina (Coord.). La tenacidad de la política: conceptos de La filosofia política: persistência y reformulación a La vuelta Del milênio. México: Instituto de Investigaciones Filosóvicas/ UNAM, 1995. p. 109-123.

GROSSI, Yonne de Souza. Belo Horizonte: qual pólis. Cadernos de História, Belo Horizonte, v. 2, n. 3, p. 12-24, out.1997. Disponível em: <http://periodicos. pucminas.br/index.php/cadernoshistoria/article/view/1666/1769>. Acesso em: 03 maio 2011.

GUIMARÃES, Berenice Martins, AZEVEDO, Sergio de (Org.). Belo Horizonte em tese. Belo Horizonte: Centro de Estudos Urbanos/UFMG, 1995.

JULIÃO, Leticia. Belo Horizonte: itinerários da cidade moderna (1891-1920). Dissertação apresentada no curso de mestrado do Programa de pós Graduação em Ciência Política da Faculdade de Filosofia e Ciências Humanas, da UFMG. Orientadora: Carla Maria Junho Anastasia.

LYNCH, Kevin. A imagem da cidade. Lisboa: Edições 70, 1996. 
MARQUES, Ivan. Cenas de um modernismo de província: Drummond e outros rapazes de Belo Horizonte. São Paulo: Ed. 34, 2011.

MELLO, Ciro Flavio Bandeira de. A noiva do trabalho: uma capital para a República. In: DUTRA, Eliana de Freitas (Org.). BH: horizontes históricos. Belo Horizonte: C/Arte, 1996. p. 11-47.

PAIVA, Eduardo França (Org.). Belo Horizonte: histórias de uma cidade centenária. Belo Horizonte: Faculdades Integradas Newton Paiva, 1997.

OILIAM, José. A propaganda republicana em Minas. Minas Gerais: Edições da Revista Brasileira de Estudos Políticos/Faculdade de Direito de Minas Gerais, 1960.

PEREIRA, Elisabeth Guerra Parreiras Baptista; XAVIER, Herbe. Imagens de Belo Horizonte de Pedro Nava. Cadernos de História, Belo Horizonte, v. 2, n. 3, p. 86-100, out.1997. Disponível em: <http://periodicos.pucminas.br/index.php/cadernoshistoria/ article/view/1686/1800>. Acesso em: 18 jul. 2012.

PINZANI, Alessandro. Republicanismo(s), Democracia, Poder. Veritas, Porto Alegre, v. 52, n. 1, p. 5-14, mar. 2007. Disponível em: <http://revistaseletronicas. pucrs.br/ojs/index.php/veritas/article/viewFile/1856/1386> . Acesso em: 10 maio 2012.

VILLAÇA, Flavio. Espaço intra-urbano no Brasil. 2. ed. São Paulo: Studio Nobel/Fapesp, 2012.

SIMMEL, Georg. A Metrópole e a vida Mental. In: VELHO, Otávio Guilherme (Org.). O fenômeno urbano. 4. ed. Rio de Janeiro: Editora Guanabara, 1987. p. 11-25.

SKINNER, Quentin. As fundações do pensamento político moderno. São Paulo: Companhia das Letras, 2009. 